\title{
Infographic:The effects of residential relocation on walking, physical activity and travel behaviour
}

\author{
Ding Ding (D) 1,2 Chloë Williamson, ${ }^{3}$ Binh Nguyen, ${ }^{1,2}$ Vincent Learnihan, ${ }^{4}$ Adrian E Bauman, 1,2,5 \\ Rachel Davey, ${ }^{4}$ Bin Jalaludin, ${ }^{6}$ Klaus Gebel ${ }^{1,2,7,8}$
}

Increasing evidence suggests that attributes of neighbourhood environments may play an important role in physical activity. ${ }^{12}$ However, nearly all studies in the field are cross-sectional and are subject to substantial bias. ${ }^{3}$ Residential relocation provides an opportunity for natural experiments where relocating to a new neighbourhood may 'interrupt' habitual behaviours and help establish new behavioural patterns. ${ }^{4}$
We conducted a systematic review on the effects of residential relocation on physical activity, walking and travel behaviour (PROSPERO registration number CRD42017077681, available at https:// www.crd.york.ac.uk/PROSPERO/display record.php?RecordID $=77681) .{ }^{5}$ We found 23 publications based on 16 studies (11 prospective and 5 retrospective), a much smaller body of research than the existing

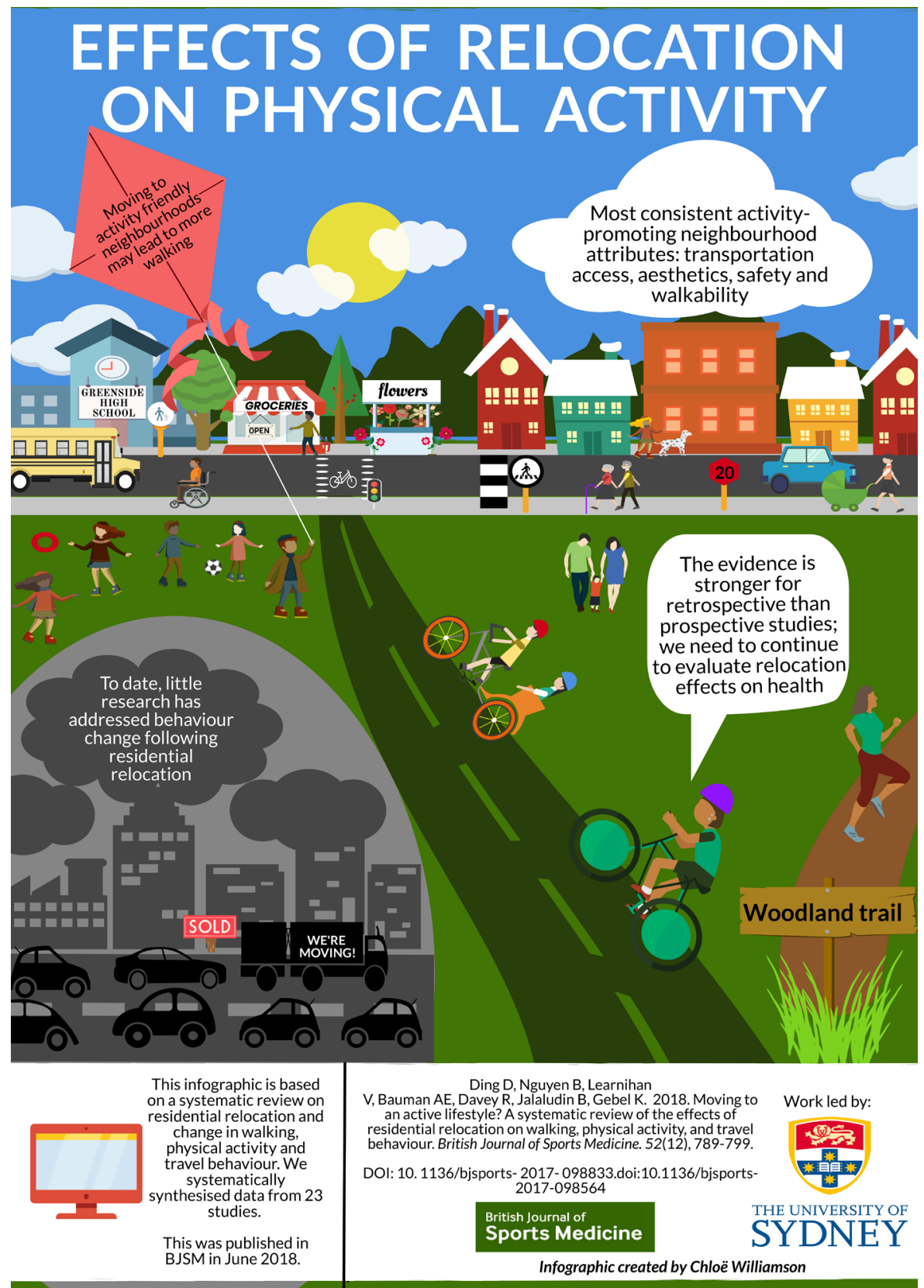

plethora of cross-sectional studies. Findings from these studies differ markedly by study design. Retrospective/quasi-longitudinal studies, which were rated lower on study quality, were more likely to report consistent evidence supporting the association between favourable changes in neighbourhood built environments and improvement in physical activity outcomes. ${ }^{6}$ The evidence was particularly strong regarding transportation access, aesthetics and crime-related safety. While prospective studies were rated higher on study quality, they tended to report less consistent associations. ${ }^{7}$ For both study designs, environmental attributes tended to have more consistent associations with walking than other measures of physical activity such as cycling. Overall, conclusions about the effects of residential relocation on physical activity outcomes are limited by the small number of studies available.

Understanding the influences of neighbourhood environments on physical activity and health is an important area of research and has strong implications for policies and practice. ${ }^{8}$ Evidence building requires incremental steps in improving research quality to move towards causal inquiry. While cross-sectional studies are important at an early stage of hypothesis testing, repeated cross-sectional studies alone are not enough to advance the field. To better understand neighbourhood influences on physical activity, evidence from longitudinal studies, evaluations of environmental interventions and relocation studies should be examined to corroborate findings from crosssectional studies. ${ }^{4}$ Residential relocation provides a unique and novel opportunity for improving the evidence base. Future studies on built environments should use longitudinal data sources, such as travel panels and cohort studies, follow up participants for longer periods, better account for self-selection and concurrent life events in relocation studies, and include evidence from geographically diverse areas, particularly from low-income and middle-income countries.

'Prevention Research Collaboration, Sydney School of Public Health, University of Sydney, Camperdown, New South Wales, Australia

${ }^{2}$ The Charles Perkins Centre, University of Sydney, Camperdown, New South Wales, Australia 
${ }^{3}$ Physical Activity for Health Research Centre, University of Edinburgh, Edinburgh, UK

${ }^{4}$ Health Research Institute, University of Canberra, Canberra, Australian Capital Territory, Australia ${ }^{5}$ Faculty of Kinesiology, University of Zagreb, Zagreb, Croatia

${ }^{6}$ Epidemiology Group, Healthy People and Places Unit, South Western Sydney Local Health District, Liverpool, New South Wales, Australia

${ }^{7}$ School of Behavioural and Health Sciences, Faculty of Health Sciences, Australian Catholic University, North Sydney, New South Wales, Australia

${ }^{8}$ Centre for Chronic Disease Prevention, College of Public Health, Medical and Veterinary Sciences, James Cook University, Smithfield, Queensland, Australia

Correspondence to Dr Ding Ding, Prevention Research Collaboration, Charles PerkinsCentre, Sydney School of Public Health, University of Sydney, Camperdown, NSW 2006, Australia; melody.ding@sydney.edu.au

Contributors CW designed the infographic. DD drafted the text. All authors contributed to the design of the infographic and approved the final version for submission.

Funding The authors have not declared a specific grant for this research from any funding agency in the public, commercial or not-for-profit sectors
Competing interests None declared.

Patient consent for publication Not required.

Provenance and peer review Not commissioned; externally peer reviewed.

(c) Author(s) (or their employer(s)) 2019. No commercial re-use. See rights and permissions. Published by BMJ.

\section{D) Check for updates}

To cite Ding D, Williamson C, Nguyen B, et al. Br J Sports Med 2019;53:1486-1487.

Accepted 12 March 2019

Published Online First 29 March 2019

Br J Sports Med 2019:53:1486-1487.

doi:10.1136/bjsports-2018-100398

\section{ORCID iD}

Ding Ding http://orcid.org/0000-0001-9850-9224

\section{REFERENCES}

1 Gebel K, Bauman AE, Bull FC. Built environment: walkability of neighbourhoods. In: Killoran A, Rayner M, eds. Evidence-based public health: effectiveness and efficiency. Oxford: Oxford University Press, 2010:298-312.
2 Sallis JF, Owen N. Ecological models of health behavior. In: Glanz K, Rimer BK, Viswanath K, Health behavior and health education: theory, research and practice. 4th edn. San Francisco: Jossey-Bass, 2015:43-64.

3 Bauman A. The physical environment and physical activity: moving from ecological associations to intervention evidence. J Epidemiol Community Health 2005:59:535-6.

4 Gebel K, Ding D, Foster C, et al. Improving current practice in reviews of the built environment and physical activity. Sports Med 2015;45:297-302.

5 Ding D, Nguyen B, Learnihan V, et al. Moving to an active lifestyle? A systematic review of the effects of residential relocation on walking, physical activity and travel behaviour. $\mathrm{Br} /$ Sports Med 2018;52:789-99.

6 Handy SL, Cao X, Mokhtarian PL. The causal influence of neighborhood design on physical activity within the neighborhood: evidence from Northern California. Am J Health Promot 2008;22:350-8.

7 Giles-Corti B, Bull F, Knuiman M, et al. The influence of urban design on neighbourhood walking following residential relocation: longitudinal results from the RESIDE study. Soc Sci Med 2013;77:20-30.

8 Sallis JF, Bull F, Burdett R, et al. Use of science to guide city planning policy and practice: how to achieve healthy and sustainable future cities. Lancet 2016;388:2936-47. 